\title{
Fases del kirchnerismo: de la ruptura a la afirmación particularista
}

\author{
Phases of Kirchnerism: from rupture to particularistic assertion
}

\author{
Francisco J. Cantamutto / francisco.cantamutto@flacso.edu.mx \\ http://orcid.org/0000-0002-6996-1534 \\ Universidad Nacional de San Martin, Consejo Nacional de Investigaciones \\ Cientificas y Técnicas, Argentina
}

\begin{abstract}
This paper analyzes Kirchnerism as a populist political process. Using specific literature, it is possible to reconstruct the change in the political and social alliances of the government, marked by the conflict with the agricultural fraction of the bloc in power in 2008. This conflict caused a change in the emphasis on the political strategy of the government, which modified its discourse and alliances. On this basis, the article proposes a periodization of the process in two stages, changing from the populist rupture to a particularistic affirmation of the Kirchnerist identity. The article shows in detail the new features of the political order after 2008.
\end{abstract}

Key words: Kirchnerism, populism, alliances, particularism, bloc in power.

Resumen: El presente artículo analiza el kirchnerismo como proceso político populista. Utilizando la bibliografía especializada, es posible reconstruir la modificación en las alianzas políticas y sociales del gobierno, marcadas por el conflicto con la fracción agropecuaria del bloque en el poder en 2008. Este conflicto produjo un cambio de énfasis en la estrategia política del gobierno, que modificó su discurso y alianzas. Con base en ello se propone una periodización del proceso en dos etapas, donde se pasa de una fase ligada a la ruptura populista del orden institucional previo a una segunda donde se produce una afirmación particularista de la identidad kirchnerista. El artículo analiza en detalle los nuevos rasgos del orden político a partir de 2008.

Palabras clave: kirchnerismo, populismo, alianzas, particularismo, bloque en el poder. 


\section{Introducción $^{1}$}

El sistema político argentino atravesó en las últimas décadas un conjunto muy amplio de modificaciones que aún son materia de debate. La consigna del "que se vayan todos" fue precedida de un largo camino de descomposición de la representación partidaria, pérdida de legitimidad por parte de las instituciones gubernamentales y un fuerte ciclo de protesta social, que quitaron bases de legitimidad al sistema político (Bonnet, 2002; Campione, 2002; Larrondo y Patrici, 2005; Yabkowski, 2012).

La oposición entre organizaciones populares y el Estado como representante de los intereses de las clases dominantes era, durante la Convertibilidad (1991-2001), frontal y clara. Esto cambió por la propia crisis que estalló a fines de 2001. Tras la sucesión de presidentes no elegidos por el voto, llega al gobierno en mayo de 2003 Néstor Kirchner, quien, al recuperar algunas de las demandas insatisfechas de las organizaciones sociales como una cadena de equivalentes relegada en el agravio neoliberal, completa el proceso de ruptura populista. ${ }^{2}$

La oposición entre las organizaciones populares y el Estado se desdibujó en este nuevo contexto, generando un nuevo orden político, signado por una discursividad novedosa. Esta sucinta caracterización ha sido desarrollada en otros trabajos (Barbosa, 2012; Biglieri y Perelló, 2007; Chavez-Solca, 2014; Muñoz, 2010; Schuttenberg, 2011).

Relativamente menos atención ha recibido la periodización interna del proceso político con el kirchnerismo como gobierno más allá de sus primeras políticas, análisis que permitiría una mejor comprensión del populismo como fenómeno contemporáneo. Una valiosa excepción en tal sentido es el

1 Las ideas discutidas en este trabajo provienen de la investigación de tesis doctoral del autor (Cantamutto, 2015). Agradezco la lectura atenta de los dos revisores anónimos que contribuyeron a mejorar el texto. Toda opinión o error contenido son exclusiva responsabilidad del autor.

2 La ruptura es entendida según la propuesta de Laclau (2006), y refiere a la confluencia equivalencial de demandas relegadas por el orden institucional previo, confluencia que se completa cuando bajo un liderazgo político logra acceder al gobierno al ganar elecciones (Cantamutto y Hurtado, 2015). Como ruptura populista, no es nunca una renovación total, y se juega más bien en el campo de las continuidades y los cambios. Para el caso argentino, el quiebre institucional se dio durante el periodo 2001-2002, que Kirchner viene más bien a enmendar, al recomponer la validez de las institucionales liberal-democráticas. No obstante, lo hace modificando el discurso, las políticas públicas y el entramado partidario, justamente bajo el marco de una ruptura de tipo populista. 
detallado estudio de Montero y Vincent (2013), cuyos aportes tienen dos diferencias centrales con nuestra aproximación: el recorte temporal (allí se limita a 2003-2007) y la consideración no sistemática de las disputas de clases y fracciones de clases. Esto lleva a postular la consolidación de una identidad kirchnerista hacia 2006, que, a nuestro parecer, aún no se distingue con claridad de una alianza política, un acuerdo entre organizaciones.

En cambio, otros estudios han señalado, creemos que con acierto, el 2008 como punto de giro para el kirchnerismo (Basualdo, 2011; Bonnet y Piva, 2013). Este artículo sostiene que se pueden distinguir dos grandes fases al interior del kirchnerismo, las cuales se caracterizan a partir de las alianzas que lo sostienen y el tipo de articulación política que propone. Como una forma del populismo de lidiar con sus propias tensiones, luego del conflicto de 2008 se dio lugar a una creciente afirmación particularista del kirchnerismo, cuyo corolario es que se puede afirmar con certeza la existencia de una identidad kirchnerista -más allá de acuerdos entre organizaciones- luego de ese conflicto.

El artículo se ordena como sigue. La primera sección explica la llegada al gobierno de Kirchner, detallando las alianzas que lo sostuvieron. La segunda sección explica la relevancia del conflicto de 2008 para la dinámica política posterior. La tercera sección analiza en detalle la nueva configuración del campo político a partir de 2008, discutiendo pormenorizadamente sus actores. Por último, se realizan comentarios a modo de cierre.

\section{La llegada al gobierno del populismo}

Se ha estudiado en detalle la descomposición del sistema político (Dikenstein y Gené, 2014; Raus, 2014; Yabkowski, 2012), el carácter disruptivo de las organizaciones y protestas populares (Campione y Rajland, 2006; IñigoCarrera y Cotarelo, 2006; Naishtat et al., 2005; Seoane, 2002; Svampa y Pereyra, 2004), y las disputas al interior de las clases dominantes (Cantamutto y Wainer, 2013; Gaggero y Wainer, 2006; Schorr, 2001) en la crisis de 2001 que llevaron a la caída del gobierno de la Alianza en ese año, dando lugar a una sucesión de presidentes transicionales: Ramón Puerta, Adolfo Rodríguez Saá, Eduardo Camaño y Eduardo Duhalde.

Este último se mantuvo en el gobierno hasta mayo de 2003 gracias a que formó una alianza entre los partidos mayoritarios -el Partido Justicialista (PJ) y la Unión Cívica Radical (UCR) - y las fracciones "productivas" de las clases dominantes - el autodenominado Grupo Productivo-, compuesto por la Unión Industrial Argentina (UIA), la Cámara Argentina de la Construcción 
(CAC) y las Confederaciones Rurales Argentinas (CRA). Se distanciaba así de la alianza predominante en el final de la Convertibilidad, cuando la banca extranjera dominó especialmente la escena, reforzando el vínculo entre aquel régimen institucional y el carácter especulativo de la acumulación.

Bajo este nuevo paraguas, Duhalde dio inicio en 2002 a una serie de políticas macroeconómicas y sociales que marcaban una distancia respecto de las imperantes hasta entonces, modificando también el discurso con el cual buscaba legitimarse. ${ }^{3}$ No obstante, el "pecado original" de no haber sido elegido por el voto junto al sesgo represivo y la exclusión de las organizaciones populares de la alianza pusieron un límite infranqueable a su gobierno.

Kirchner, quien llegó a la presidencia de la mano de Duhalde, pudo superar estos escollos. A pesar de haber ganado por una minoría del electorado (22.24\% de los votos válidos; $16.9 \%$ del electorado habilitado), contaba con la validación institucional de la que carecía su predecesor. ${ }^{4}$ Abandonando la confrontación directa, y promoviendo en cambio instancias de diálogo directo con organizaciones populares, junto a los planes sociales ya entonces masivos, las políticas novedosas en materia de Derechos Humanos y los efectos visibles de la reactivación económica, le dieron a Kirchner la posibilidad de erigirse en líder post hoc del proceso de ruptura con el régimen neoliberal. Esto es; se pudo postular como heredero de esa resistencia al neoliberalismo, incluso sin haber sido parte de ella.

La fuerza combinada de un discurso que recuperaba aquellas demandas, un conjunto de políticas públicas orientadas a atender necesidades populares largamente relegadas, bajo una figura carismática, que se proponía como representante del pueblo agraviado por el bloque en el poder (en adelante, $\mathrm{BEP})$, son algunos elementos que explican este proceso como populismo

3 En términos de políticas públicas, se destacan la devaluación, la pesificación y congelamiento de las tarifas de los servicios públicos, la pesificación asimétrica de depósitos y préstamos con el sistema bancario, la negociación "realista" de la deuda externa y la masificación de los planes sociales. El discurso de Duhalde, de la mano de la Iglesia católica, resaltó los valores de la producción contra la especulación, del empleo y la industria como formas concretas de la inclusión social. Este cambio de discurso, junto a nuevas políticas macroeconómicas y sociales, daría inicio a un cambio en la relación entre Estado y clases populares (Muñoz, 2010), que el gobierno de Kirchner explotó en mayor intensidad.

4 Kirchner salió segundo en las elecciones, pero su contrincante, el ex presidente Menem, se negó a participar de la segunda vuelta, sabiendo que Kirchner capitalizaría todo el voto que se le oponía. De haberse llevado a cabo la segunda vuelta, Kirchner podría haber asumido con un mayor capital político. Esta necesidad de construir legitimidad luego de ganar la elección posiblemente motivó parte del protagonismo activo del flamante presidente (véase especialmente Montero y Vincent, 2013). 
(Aboy-Carlés, 2005 y 2013; Laclau, 2006). ${ }^{5}$ Esta primera fase del proceso ha sido ya estudiada en detalle por la bibliografía referida en la introducción.

Estos estudios han relegado relativamente la importancia de la alianza con algunas fracciones del BEP y su impacto en forma concreta de la reactivación económica (Balsa, 2010; Féliz y López, 2012). Concretamente, sostenemos que el kirchnerismo consolidó un orden político de tipo hegemónico, donde la fracción industrial se erigió como dirigente dentro del BEP (Cantamutto, 2016). ${ }^{6}$ El problema empírico de este olvido metodológico resulta, en algunos casos, en un salto ilegítimo de la forma populista del proceso político a su carácter de representante de sectores populares (Aboy-Carlés, 2013). El kirchnerismo, como proceso de ruptura populista, incluyó en su apelación (y sus alianzas) a fracciones del BEP, y se distanció de otras fracciones, a las que asimiló en el discurso al conjunto de las clases dominantes, como amenaza permanente al bienestar del pueblo.

Nos interesa dejar asentada la composición de la alianza o coalición que el kirchnerismo formó. En esta primera fase, bajo la propuesta de la transversalidad (véase Montero y Vincent, 2013), el gobierno logró convocar diversas fuerzas sociales y políticas:

a) Entre las clases dominantes:

Se consolidó la alianza con la UIA y CAC, quienes serían interlocutores privilegiados y principales beneficiarios de las políticas públicas. Se sumaron además asociaciones de bancos de capital local (ABAPPRA y ADEBA), la Bolsa de Comercio, y cámaras ligadas a empresas de mediana escala (APYME y CAME). Al mismo tiempo, y afianzando la división al interior del BEP, se consolidó el alejamiento de las entidades representativas del agro (CONINA-

5 La posición de Aboy-Carles se distingue de la de Laclau, pues el primero ha señalado que el respeto por la institucionalidad liberal-democrática posterior a 1983 limita la posibilidad de hablar de populismo en Argentina. Aunque quizás sin el ímpetu del peronismo clásico $\mathrm{u}$ otros populismos contemporáneos de la región, entendemos que el kirchnerismo presentó una vocación refundacional que no siempre se restringió a estos canales, o los puso en tensión en más de una oportunidad, especialmente después de 2011. Sin anular las discrepancias entre estos autores, creemos que comparten una mirada general del proceso político que es complementaria, y en todo caso, ambos aportan elementos teóricos utilizados por los estudios empíricos señalados en la bibliografía.

6 El BEP comparte acuerdos básicos en torno a determinantes generales de las relaciones de explotación y dominación de una sociedad, pero incluye también disputas internas por dirigir el proceso, poniendo demandas y proyectos de una parte del mismo como el programa de todo el BEP, y, en el mejor de los casos, del conjunto de la sociedad. Esta disputa por la hegemonía, pues, implica disputas entre clases, pero también al interior de las clases dominantes (Poulantzas, 1980). 
GRO, CRA, FAA y SRA), del capital financiero extranjero (ABA) y de los servicios públicos (ADESPA)?

b) Entre los partidos politicos:

El kirchnerismo compuso el Frente para la Victoria $(\mathrm{FpV})$ a partir de la unión del Partido de la Victoria (escindido del PJ) y el Frente Grande, a la que se sumaron el Partido de la Revolución Democrática y el Polo Social. El Partido Intransigente se incorporó después. En un primer momento, Política Abierta para la Integridad Social (PAIS) y el Partido Comunista (PC) Congreso Extraordinario también participaron de la alianza, a la cual incluso la UCR y el recién unificado Partido Socialista (PS) apoyaron de forma más laxa.

Todos estos últimos partidos se distanciarían más tarde, aunque dejarían un legado importante de representantes en el propio gobierno. En particular, el radicalismo tendría una escisión proveniente de dirigentes exitosos a nivel subnacional, que se integrarían entre las filas del gobierno (conocidos como "radicales K"), siendo el vicepresidente de Cristina Fernández, Julio Cobos, el más visible.

c)Entre las organizaciones populares:

Las organizaciones populares habían sido las grandes protagonistas de la protesta social que erosionó al orden neoliberal, tal como se erigió en los noventa. Se pueden distinguir dos grandes grupos relevantes. Por un lado, tenemos a las organizaciones defensoras de Derechos Humanos, que tuvieron un acercamiento muy rápido al gobierno, de la mano de las nuevas políticas en esta materia: Madres de Plaza de Mayo, Abuelas de Plaza de Mayo, el Centro de Estudios Legales y Sociales, Hijos e Hijas por la Identidad y la Justicia contra el Olvido y el Silencio, y la Asamblea Permanente por los Derechos Humanos, fueron algunas de las reconocidas entidades que se identificaron con el gobierno, generando una transferencia simbólica muy significativa. Otras organizaciones (como CORREPI o Madres de Plaza de Mayo Línea Fundadora) mantuvieron mayor distancia.

Por otro lado, entre las organizaciones territoriales y de desocupados -el movimiento "piquetero"- también cambió la interpretación sobre el gobierno. Sintéticamente, las organizaciones con mayor tradición de corte nacionalpopular o nacional-revolucionaria se sintieron más cercanas al discurso del

$7 \mathrm{ABA}=$ Asociación de Bancos de Argentina; ABAPPRA = Asociación de Bancos Públicos y Privados de la República Argentina; ADEBA = Asociación de Bancos Privados de Capital Argentino; ADESPA = Asociación de Empresas de Servicios Públicos Argentinos; APYME = Asociación de Pequeñas y Medianas Empresas; CAME = Confederación Argentina de la Mediana Empresa; CONINAGRO = Confederación Intercooperativa Agropecuaria; FAA $=$ Federación Agraria Argentina; SRA = Sociedad Rural Argentina. 
gobierno. Aunque con diversos grados de identificación, se aliaron ya en 2004 como un frente de organizaciones kirchneristas, la Federación Tierra y Vivienda (FTV), el Movimiento de Unidad Popular (MUP), el Frente Transversal Nacional y Popular, el recién creado Movimiento Evita (ME) y Barrios de Pie (BdP). Estas organizaciones otorgaron el componente específicamente popular -en su acepción "sociométrica" - al kirchnerismo, carente por completo antes de ser gobierno de cualquier relación con los movimientos disruptivos del orden neoliberal. Otro conjunto de organizaciones no se alió al gobierno, manteniendo su distancia crítica o frontal oposición, siendo catalogados por éste y la prensa como "piqueteros duros".

d) Entre las centrales sindicales:

El gobierno logró el pleno apoyo de la Confederación General de Trabajadores (CGT), unificada desde 2004 y gran ganadora de la rehabilitación de la negociación colectiva de trabajo (Casas, 2011). Esta alianza permitiría hacer creíble la apelación del gobierno a su carácter de representante de los trabajadores. Una parte de la Central de Trabajadores de la Argentina (CTA), en particular, organizaciones territoriales que formaban parte de ella (algunas de las referidas en el anterior inciso), se acercaron al gobierno, aunque la dirigencia se mantuvo crítica. En cualquier caso, la CTA tuvo más dificultades en orientarse como una oposición sistemática.

Aunque el listado anterior resulta un tanto esquemático, sirve de base para comprender el armado concreto de la alianza que sostuvo al kirchnerismo durante esta primera etapa abierta en mayo de 2003 y que se cierra en julio de 2008 (véase sección $2^{9}$ ). Debe señalarse que no todos los actores sociales recién mencionados tuvieron igual relación con el gobierno ni entre sí, manteniéndose diversas inequidades en las relaciones de poder. Los cambios en las identificaciones políticas de las organizaciones sociales, particularmente el movimiento de trabajadores desocupados, fueron más estudiados (Cortés, 2010; Muñoz, 2004; Natalucci y Schuttenberg, 2013; Perelmiter, 2010; Retamozo, 2011; Schuttenberg, 2011). Sin embargo, en esos primeros años persistían las dudas respecto de la emergencia de la identidad kirchnerista (De Ípola, 2005); es decir, un proceso que superara las alianzas para fundar una articulación novedosa. Es difícil hablar, pues, de una nueva identidad política, incluso si esta alianza ganó elecciones. Nos interesa señalar cómo cambió esta situación a partir de 2008.

8 En general, eran organizaciones ligadas a distintos partidos de izquierda marxista, aunque también se mantuvieron críticas aquellas incluidas dentro de la izquierda independiente.

9 Dicha sección se encuentra en la página 70: La inflexión de 2008: el conflicto "Campo vs Gobierno" [Nota del editor]. 


\section{La inflexión de 2008: el conflicto "Campo vs Gobierno"}

Combinando la recomposición institucional con la vocación de renovación democrática a través de políticas públicas, continuidad y cambio, en una macroeconomía relativamente ordenada, Cristina Fernández de Kirchner pudo ganar por amplia ventaja las elecciones presidenciales de octubre de 2007. Pero ante el estallido de la crisis internacional y el desgaste interno de los "superávit gemelos” (el fiscal y el externo; véase Cantamutto y Costantino, 2016), el equipo económico buscó implementar una modificación en la alícuota de los derechos para exportaciones (retenciones) de productos primarios, proponiendo un esquema de tasa móvil. La resolución núm. 125 de marzo de 2008 ordenaba que, según las variaciones de precios internacionales, se ajustara la alícuota del tributo, lo cual en la perspectiva de ese mes significaba un aumento. Este cambio produjo una fuerte reacción por parte del capital agropecuario.

Si bien el conflicto de 2008 inició con un reclamo económico-corporativo por apropiación de la renta, el desarrollo del mismo generó una disputa política más general (Basualdo, 2011; Bonnet, 2012; Svampa, 2011). El agro argentino había experimentado un proceso de concentración y agriculturización (sojización, en específico), que modificó su estructura social. Tras la devaluación de 2002, los pequeños productores sobrevivientes se acercaron lentamente a las posturas políticas de los grandes terratenientes (Costantino, 2013). Es decir, para 2008 estaban dadas ciertas condiciones de confluencia política, que el capital agroexportador concentrado explotó en la polarización antagónica, impidiendo que otros actores del sector formaran parte de la disputa (Castro-García et al., 2009). La falta de consideración por parte del gobierno de situaciones diversas al interior del sector agropecuario -por ejemplo, los reclamos por diferenciación de FAA- facilitó la apelación por parte de las entidades representativas de sus fracciones más concentradas (SRA y CRA) al conjunto. ${ }^{10}$

Así, se formó la Mesa de Enlace, que reunió a las cuatro asociaciones más importantes del sector: SRA, CRA, CONINAGRO y FAA. Esta confluencia entre las mayores organizaciones de productores agropecuarios no había existido nunca antes, y contó con la anuencia expresa de otras asociaciones ligadas a otros tramos del negocio agrario. Debe resaltarse además el rol de

10 Este conflicto acercó posiciones al interior del complejo agroindustrial de conjunto. Entre las organizaciones de productores rurales, FAA tuvo hasta ese momento una relación más ambigua con el gobierno, reclamando en coyunturas específicas y negociando en otras. Las demás asociaciones tuvieron una distancia crítica más sistemática respecto del kirchnerismo. 
los grandes multimedios, especialmente de los grupos Clarín y La Nación, en la construcción del conflicto y sus actores, pues promovieron de manera expresa y reiterada la identificación del reclamo con un genuino interés patriótico -bajo la apelación de "el campo somos todos"- ante la intervención ilegítima del gobierno (Aronskind y Vommaro, 2010).

La cobertura mediática promovió una lectura que trataba el problema como una disputa entre dos "bandos"; por un lado, ciudadanos independientes interesados en el bienestar del país, y por el otro, militantes "comprados" con la política social, la expresión más plebeya del supuesto saqueo de los recursos públicos por la corrupción kirchnerista.

Sin embargo, esta autoidentificación como "el campo" de la Mesa de Enlace facilitó al gobierno la construcción de una cadena de equivalencias sobre este significante, asociándolo a oligarquía-dictadura-golpismo-antipueblo (Guerrero-Iraola, 2011). Ante tal articulación antagónica, el gobierno se erigía como representante del pueblo, legítimo representante de la totalidad política, avalado por el reciente voto de amplia mayoría, acusando a la vez a sus antagonistas de funcionar como corporaciones de intereses espurios. El efecto de esta defensa fue un clima de mayor antagonismo (Artese et al., 2012; CastroGarcía et al., 2009), que obligaba a los actores políticos y sociales a posicionarse en uno u otro polo. $\mathrm{Y}$ en ambos se buscaba apelar a la defensa de todo el pueblo argentino.

Esto supuso dos innovaciones (Cantamutto y Hurtado, 2015). Por un lado, el gobierno buscó legitimarse a través de la validación institucional, cuando su propio origen responde a una ruptura con el orden institucional previo; y por otro, esta reacción menoscabó su estrategia de alianzas, pues ya no habría incorporación -ni intento- de otros actores, sino confirmación y afianzamiento de la fuerza propia.

Ambos elementos suponen un cambio en el orden de prelación del populismo, abandonando relativamente su componente de ruptura: sin intentos por ampliar su articulación y bajo la defensa del orden institucional. Ante esto, la Mesa de Enlace apelaba al imaginario de una Argentina supuestamente próspera de la etapa agroexportadora (1870-1930), el "Granero del mundo”, pero era incapaz de ampliar sus demandas más allá del reclamo fuertemente corporativo de no subir las retenciones a la exportación de soja.

La presidenta pudo así satirizar el carácter espurio de la ganancia del agro, debida a los altos precios internacionales, que no exigía ningún esfuerzo por parte de los productores. ${ }^{11}$ Para un gobierno que decía defender un 11 En un discurso en el Salón Blanco de la Casa Rosada, el 31 de marzo, dijo que "la soja es, en términos científicos, prácticamente un yuyo que crece sin ningún tipo, digamos, de cuidados especiales". 
proyecto de nación basado en la inclusión y el trabajo, las ganancias que se basaban en privilegios y suerte eran inmerecidas. ${ }^{12} \mathrm{El} 1 \mathrm{de}$ abril la presidenta explicó el argumento político: se trataba de una minoría corporativa que ponía en riesgo los intereses comunes de la nación, atentando desde dentro de la comunidad contra el bienestar del conjunto, y que, por lo tanto, el gobierno, en calidad de representante de la totalidad, tenía derecho a decidir sobre la parte.

En ese discurso, el gobierno validaba su accionar en las instituciones democráticas (con la Constitución como máxima referencia) y en el voto popular, una doble referencia de legitimidad, característica del populismo, con las que no contaban sus interlocutores. Debe notarse que, a pesar de las acusaciones, la presidenta no excluyó de la comunidad a los manifestantes, sino que los llamó a reflexionar, a recapacitar. Esto es otra nota típica del populismo, que juega en el corrimiento de la frontera interna del orden político, sin buscar una exclusión total de la posición antagónica (Aboy-Carlés, 2013).

Finalmente, cuando la presidenta hablaba en ese discurso del 1 de abril en nombre de los y las argentinas, del pueblo, dio una enunciación no exhaustiva de quienes lo integraban: industrias, pequeños y microproductores, incluidos los del sector agrícola (horticultores). Tal como hiciera Néstor Kirchner al asumir, el gobierno no habla sólo en nombre de la plebs, sino que involucra explícitamente a lo que Duhalde había llamado la alianza productiva. El populus legítimamente democrático era heterogéneo en su composición de clases.

Se trazaba así una nueva frontera al interior de la comunidad política, pues ya no eran los sectores especulativos quienes representaban la amenaza neoliberal al pueblo (acorde con la mayor presencia económica y política de la fracción financiera del BEP como aliada del gobierno), sino las corporaciones que defendían ambiciones particulares y atentaban contra el todo, poniendo sus reclamos por encima de los intereses de la Patria. Se resaltó así el sesgo anti-democrático y anti-popular del reclamo del capital agrario, basándose en el carácter particular de la corporación. Este corrimiento del antagonismo interno marcó la dinámica política del periodo posterior, no sólo respecto del BEP sino con las clases populares.

12 Existió un argumento complementario, relativo a la necesidad de redistribuir la renta del suelo entre diferentes sectores sociales, en lo que el gobierno refirió como "modelo de acumulación con matriz diversificada e inclusión social" o "modelo de producción y trabajo". Según proponía el gobierno, se trataba de aprovechar una parte de esta renta para mejorar las condiciones de vida de la población no sólo mediante políticas sociales, sino también mediante el impulso a actividades con capacidad de creación de empleo: la industria y la construcción. Para ello, se utilizó una parte creciente de la recaudación para subsidiar el costo de los servicios públicos, mejorando la rentabilidad industrial (Cantamutto, 2016). 
La distinción de quiénes personificaban la amenaza ya no tenía arraigo en valores e ideas (conservadores o neoliberales) ni en ocupaciones (finanzas, especulación) o en distorsiones de la función (corrupción) como al inicio del mandato apuntaba Kirchner, sino en el carácter particular de la demanda. ¿Cuándo una demanda era particular, y por ello corporativa? Cuando contrariaba el programa del gobierno, votado por la mayoría, y por ello, defensor de la comunidad completa. Corporación pasaría a ser todo aquel grupo que cuestionara el orden discursivo y político propuesto desde el gobierno.

Esta defensa agregó conflictividad, facilitando la confluencia organizativa de las asociaciones del agronegocio, a las que se acercaron rápidamente algunos partidos políticos. Esta interacción entre la Mesa de Enlace y los partidos ayudó a construir un discurso más amplio para el reclamo, apelando a un imaginario de una Argentina cuya prosperidad se basa en la pujanza del sector agropecuario. Así, los reclamos incorporaron, por ejemplo, la crítica a la concentración de poder en manos de la flamante presidenta, argumento de corte republicano, que acusaba al gobierno por su decisionismo, asociando esta característica a un modelo populista irrespetuoso de las instituciones democráticas (Fair, 2009; Rodríguez y Freibrun, 2011). Ante su pérdida de gravitación al interior del BEP, las fracciones agropecuarias apostaron a llevar al Congreso el conflicto, donde las diversas fracciones del capital encuentran mayor representatividad (Bonnet y Piva, 2013; Poulantzas, 1980).

La "recuperación de la política" (Rinesi, 2011) era vista, en definitiva, como una mediación estatal permanente, asistemática y costosa, que debía reemplazarse por un régimen más previsible. Durante el periodo 2003-2007 parecía que todo el BEP podía ganar, y el conflicto por la intervención se diluyó, pero cuando alguien debía ceder, los ánimos cambiaron. En efecto, el conflicto terminó en julio de 2008 con un decisivo voto "no positivo" (sic) en el Senado de la Nación, donde el vicepresidente Julio Cobos votó contra su propio gobierno. Se marcaron así las diferencias ideológicas y políticas (abandonaron el gobierno por este conflicto el ministro de Economía Martín Lousteau y el jefe de gabinete Alberto Fernández).

El voto marcó, en definitiva, el final de la transversalidad (Moreira y Barbosa, 2010). Que la resolución haya provenido del vicepresidente Cobos, un "transversal" del radicalismo, le dio al gobierno una salida al largo conflicto, pues quien cedía a la presión era un representante de otro partido. Esto implicó un cambio de prioridades para el gobierno, en una nueva estrategia, que combinaba la construcción de una fuerza política propia con el vuelco hacia el PJ. 
Entre los partidos políticos y las fuerzas de las clases populares, la tensión por alinearse con el gobierno o quedar con "el campo" inauguró un nuevo momento político. El gran problema era que, si bien el discurso de la Mesa de Enlace se amplió para interpelar otros actores sociales, las demandas de estos últimos no fueron en absoluto consideradas, manteniendo hasta el final un reclamo de tipo corporativo. El kirchnerismo, por su parte, reaccionó reafirmando su particularidad. Veamos en detalle.

\section{Efectos sobre el campo político}

La impugnación del orden político por parte de una fracción del BEP produjo una serie de modificaciones sobre la dinámica política argentina, que presentamos a continuación, dividida a sólo los efectos expositivos.

\section{Patrón de reproducción económica y politicas públicas}

El patrón de reproducción económica mostró algunos cambios en la fase abierta en 2002 (Féliz y López, 2012). La fuerte desvalorización de la fuerza de trabajo se complementó con una devaluación y la cesación de pagos de la deuda, que lograron expresarse de conjunto en los superávit "gemelos": externo y fiscal. Para este resultado, la intermediación estatal entre fracciones del capital era clave, al mismo tiempo que producía un desgaste político por su permanente acción explícita. A medida que los salarios se recuperaban, la inflación desgastaba la competitividad obtenida por la devaluación y los pagos de deuda se reanudaron -tras la negociación de 2005-; los superávit comenzaron a erosionarse. El estallido de la crisis mundial agregó un componente externo a este escenario.

Tras el conflicto de 2008, estas tensiones se acrecentaron. En relación con la dinámica política que nos interesa aquí, desde 2008 el salario medio real se estancó y el desempleo dejó de descender, limitando las mejoras estructurales a la clase trabajadora. La inflación, en cambio, se incrementó, estabilizándose en los dos dígitos. ${ }^{13}$ La industria y la construcción, principales fuentes de empleo, perdieron su dinamismo, siendo reemplazadas por la intermediación financiera como el sector que más creció en esta nueva etapa.

13 La intervención del instituto oficial de estadísticas (el INDEC) desde 2007 ocasionó múltiples problemas en las estimaciones disponibles. Esto hace muy difícil ser taxativos respecto de cualquier dato estadístico de esta etapa. Respecto de la dinámica del mercado de trabajo, se puede afirmar que perdió el dinamismo de la primera etapa sin por ello entrar en una crisis, persistiendo una importante heterogeneidad interna. 
El superávit comercial primario fue erosionándose, volviéndose cada vez más difícil cubrir déficit industrial y energético, los pagos de deuda y sus intereses, la remisión de utilidades al exterior y la fuga de capitales.

Las principales intervenciones del gobierno no modificaron los determinantes estructurales del modo de desarrollo (véase discusión en Cantamutto y Costantino, 2016). Una excepción importante es la reforma de la carta orgánica del Banco Central en 2012, que lo subordinó a la política oficial, recuperando su control de las manos del capital financiero. Existieron otras intervenciones relevantes: a) la nacionalización de dos empresas, Aerolíneas Argentinas y Yacimientos Petrolíferos Fiscales y la recuperación de la previsión social con la estatización de las Administradoras de Fondos de Jubilaciones y Pensiones; ${ }^{14}$ b) desde 2011 se intervino el mercado financiero y la balanza de pagos con algunas regulaciones novedosas; c) la implementación de la Asignación Universal por Hijo/a. Aunque las mencionadas intervenciones no agotan el accionar estatal de la fase, resultan posiblemente las que mayor impacto simbólico tuvieron, en particular a) y c), pues se trata de políticas de regulación largamente demandadas por organizaciones populares.

En esta fase se intensificó la actividad en materia de ampliación de derechos. En 2009, se aprobó la ley núm. 23,298 Orgánica de los Partidos Políticos, que reglamentó las internas abiertas obligatorias, y la ley núm. 26,522 de Servicios Audiovisuales, conocida como ley de medios. Esta última corporizó el enfrentamiento con el multimedios Clarín, recuperando un proyecto largamente impulsado por medios comunitarios. El rol de los multimedios en la construcción del conflicto de 2008 puso sobre la mesa la necesidad del gobierno de modificar la estructura del sistema mediático.

Como parte del mismo enfrentamiento, se dio inicio al programa de Fútbol para Todos, que quitó la transmisión de los torneos locales - un negocio multimillonario- al multimedios. En 2010 se aprobó la ley núm. 26,618 de Matrimonio Igualitario, permitiendo la unión legal entre personas del mismo sexo. En mayo de 2012 se aprobó la ley núm. 26,743 de Identidad de Género, reconociendo la potestad de cada persona de determinar su condición de género, y reconociéndole derechos de tratamiento médico correspondientes. Debe enfatizarse además que en estos años se llevó adelante casi la totalidad de los juicios por crímenes de lesa humanidad (Cantamutto, 2015).

14 Todas estas medidas tuvieron un fuerte impacto simbólico, debido a que se trató de la reversión parcial de algunas de las privatizaciones insignia de la década previa. En el caso del sistema de pensiones, se proveyó además al Estado una muy importante fuente de recursos para financiar diversas políticas: planes hipotecarios (PROCREAR), de inclusión tecnológica (Conectar Igualdad), de sostén del empleo privado (REPRO) y la antes referida AUH, entre otras. 
El conjunto de políticas públicas aquí referidas resultó de gran peso en una disputa cultural de corte progresista. Una caracterización general compartida es que no afectaron al patrón de reproducción económica, sino que se orientaron en un sentido diferente de la disputa, y tuvieron un muy elevado impacto simbólico (son referidas por casi todo militante kirchnerista como fundamento de su apoyo). El kirchnerismo eligió como campo de disputa política una serie de áreas que no afectaran sus alianzas con las clases dominantes, o enfrentamientos específicos con algunas fracciones del BEP (ciertos multimedios, el "campo"). ${ }^{15}$

\section{Las clases dominantes}

El nudo de la disputa al interior del BEP se estructuró por el rechazo de la fracción agropecuaria a aceptar su posición ambivalente de menor poder político pero de afianzamiento de su poder estructural. Esta brecha entre lo político y lo económico sólo se expresó con total claridad en esta fracción, cuyo reconocimiento impulsó a la dirigencia agropecuaria a lanzar una impugnación al orden político hegemonizado por el capital industrial (Cantamutto, 2016).

Se inauguró así una nueva fase en la conflictividad social, donde organizaciones patronales ocuparon el espacio público con repertorios asociados a las clases populares (Antón et al., 2011). Si para el capital agropecuario el problema era expandir su interpelación a otros sectores sociales, al capital industrial se le planteaba el dilema de hasta qué punto le eran útiles los mecanismos de estructuración del orden político. Dicho de otra forma, la intervención del Estado para arbitrar entre fracciones del BEP y de éste con las clases populares pasó a ser demasiado costosa, económica y políticamente.

Como decíamos en Cantamutto y Hurtado (2015), los capitales agropecuarios buscaron presentarse como referentes para un conjunto social más amplio, nucleando descontentos más amplios con las políticas gubernamentales como parte de sus reclamos. Para ello, apelaron a referencias históricas arraigadas en el imaginario nacional; en especial, la de Argentina como "Granero del mundo". La gran difusión de esa imagen de supuesto bienestar

15 El excelente trabajo de Waiman (2012) explica los límites de la disputa cultural para el caso argentino. El gobierno dio continuidad a todo un conjunto de políticas estructurales que favorecían la limitación del conflicto con el conjunto del BEP, entre las que se destacan la promoción del extractivismo -agrario y minero-, las leyes de flexibilización laboral, el tratamiento de la inversión extranjera, la ausencia de una revisión tributaria general, y la política de pagos de la deuda pública sin auditoría, entre otras. 
-transmitida por décadas a través de la historia oficial enseñada en las escuelas del país- permitía hacer una lectura diferente del pasado, buscando la promesa de la nación que puede cumplir su destino de grandeza pero es amenazada desde adentro.

La propuesta no era novedosa: era la visión liberal de la historia ensayada desde la aparición del peronismo. En esta visión de la sociedad, Argentina tiene sólo un destino posible y es aceptar que su prosperidad depende de que el sector agropecuario responda a lo que el mundo espera del país, bienestar permanente amenazado por la intervención innecesaria y arbitraria del Estado (Panero, 2011).

Esta interpelación facilitaba que sectores medios urbanos sin intereses directos en el sector pudieran plegarse al reclamo, canalizando sus descontentos como parte del mismo conflicto. No en vano uno de los actos más masivos y de mayor importancia política fue realizado en el Monumento a la bandera en Rosario, el 25 de mayo (aniversario de la Revolución de 1810), entonando el himno nacional como principal fuente de autoidentificación.

Tal como explica con claridad Panero (2011), la Mesa de Enlace interpretaba que el interés del campo es el interés de la sociedad entera: "sin campo, no hay Argentina”. El acto de Rosario fue, justamente, en el centro de la zona núcleo productora de soja, componiendo una perfecta imagen de lo que la Mesa de Enlace entendía por economía, política y bienestar social. Pero justamente esta estrechez de miras a la hora de incluir otras demandas sociales en sus propios intereses limitaba la capacidad de interpelación del llamado del agro, por masivo que pareciera. Debe recordarse que, en todo momento, la demanda concreta que aglutinó fue derogar la resolución núm. 125, sin tomar nunca en cuenta otros reclamos.

La respuesta del gobierno, como explicamos, fue radicalizar esta polarización con su estrategia: insistir en su legitimidad como gobierno electo por una amplia mayoría frente a un grupo particular con demandas corporativas (Cantamutto y Hurtado, 2015). Si las opciones polares ponían al agro y al gobierno en los extremos, vale señalar que con este último se encontraban la UIA, CAC y ADEBA, reclamando a la Mesa de Enlace que detenga las protestas (Cotarelo, 2008; Sanz-Cerbino, 2012). Beneficiarios directos de las políticas públicas que redistribuían la renta de la tierra, estas cámaras expresaban preocupaciones sinceras y propias al respecto.

De conjunto, la impugnación del orden político (el "relato" y las políticas públicas) por parte de la fracción agropecuaria mostró las dificultades de subordinar sus intereses al interior del propio BEP. Sin embargo, debido al carácter restringido - corporativo- de sus demandas, esta impugnación 
no alcanzaba para construir un nuevo orden. Durante este periodo, el BEP buscó los acuerdos mínimos que le permitieran realizar demandas conjuntas, entre las que se resaltaron las de previsibilidad, protección del derecho de propiedad, resolución del problema de la deuda, fortalecimiento de la competitividad (contención de salarios y ajuste del tipo de cambio). A estas propuestas se pueden sumar las de respeto al Estado de Derecho y la necesidad de preservar la división de poderes, según se expresaron en el Foro de Convergencia Económica de cara a las elecciones de 2015.

Accesoriamente, la crítica del gobierno al ánimo destituyente de la patronal agropecuaria, a la que se vinculaba - no sin razón- a los golpes de Estado históricos, hace aparecer un "nuevo" enemigo del pueblo, antes ausente en el discurso oficial. Aparece la crítica a los medios de comunicación, que ofrecían una cobertura de los hechos que el gobierno consideraba distorsionada y parcial (Aronskind y Vommaro, 2010). ${ }^{16}$

La presidenta criticó como mensaje "cuasi mafioso" a la caricatura aparecida en el diario Clarín, donde aparecía amordazada. A partir de este conflicto, el multimedios pasó a ser la personificación por antonomasia de la corporación. La "corpo" - como se la llamó- se tornaría en el principal enemigo del pueblo, volviéndose probablemente el exterior constitutivo más fuerte del kirchnerismo: “Qué te pasa, Clarín? ¿Estás nervioso?”, le espetó Kirchner en marzo de 2009.17

El conflicto con el agro y con el grupo Clarín serían ejes del antagonismo político en esta fase. Al interior del BEP, este antagonismo produciría un creciente desgaste, sin por ello quebrar el apoyo de algunas fracciones del capital al gobierno. Debe, además, enfatizarse el evidente acercamiento entre éste y las fracciones ligadas a la actividad financiera.

\section{Partidos políticos}

A partir de la tensión antagónica "campo-gobierno", no sólo las apelaciones del gobierno fueron fructíferas en movilizar apoyos, sino también las del

16 "Esta vez no han venido acompañados de tanques, esta vez han sido acompañados por algunos 'generales' multimediáticos que además de apoyar el lock out al pueblo, han hecho lock out a la información, cambiando, tergiversando, mostrando una sola cara", dijo la presidenta en su discurso del 1 de abril de 2008, Acto por la convivencia y el diálogo realizado en la Plaza de Mayo (Fernández de Kirchner, 2008).

17 El enfrentamiento con el agro y con Clarín son una referencia casi permanente en la enumeración de hitos que acercaron nuevos militantes al kirchnerismo (Vázquez y Vommaro, 2012). 
capital agrario. Algunos partidos intentaron rápidamente ligarse sus reclamos: Propuesta Republicana (PRO), la Coalición Cívica (CC) y la UCR fueron los más abiertos en esta intención. El reclamo del agro era leído desde el liberalismo (no intervención del Estado) y desde el republicanismo (división de poderes), por lo que fueron las principales corrientes político-ideológicas desde las que los partidos intentaron representar la demanda y expandir el horizonte de interpelación.

Como espejo, el gobierno enfatizó su componente nacional-popular (Fair, 2009). El éxito electoral de la opción oficial llevó a los partidos mayoritarios de oposición -a excepción del PRO, que funcionó como polo antagónico- a combinar la crítica liberal-republicana con continuidades progresistas.

Una vez que Cristina Fernández asumió, Kirchner se orientó a normalizar el PJ y aprovechó la presidencia del partido para apoyar al gobierno durante el conflicto de 2008. Esto tensó aún más las relaciones con el resto del PJ, cobrando nuevos bríos la disputa por definir cuáles eran los valores e ideas que defendía el peronismo, donde -esquemáticamente- el Peronismo Federal enfatizaría los rasgos de orden frente al carácter refundacional del kirchnerismo. Los esfuerzos de Kirchner por mantener unido al PJ entraban en conflicto tanto con los dirigentes peronistas con proyectos propios, como con las fuerzas no peronistas del FpV. BdP-Libres del Sur rompió con el gobierno a fines de 2008, expresando su descontento con el vuelco hacia el "pejotismo". El radicalismo que apoyaba al gobierno se dividió entre quienes volvieron a la UCR opositora y quienes se mantuvieron como "radicales K". Entre estos últimos se conformó el Partido de la Concertación-FORJA, en alusión a la histórica agrupación radical que fuera fuente ideológica para el peronismo.

A la vez que viejas alianzas se quebraban, otras nuevas surgían. A principios de 2009 aparece en la escena nacional el Frente Nuevo Encuentro, que reúne al partido Encuentro por la Democracia y la Equidad, Espacio Solidaridad e Igualdad (SI), el PC, Movimiento Libres del Sur y el Instrumento Electoral por la Unidad Popular (estos dos últimos se irían del Frente a pocos meses de su creación).

El perfil de este agrupamiento, en el marco de la tensión restrictiva (Varesi, 2013) de la polarización entre gobierno y oposición de centro-derecha, sería el de una fuerza independiente que apoya al gobierno. Una suerte de kirchnerismo por fuera del FpV. Esta idea atrajo a diferentes fuerzas con presencia en el Congreso, entre los que se destacan el Partido Solidario (Carlos Heller) y la línea interna del PS de Ariel Basteiro y Jorge Rivas, que lanzaron en 2011 el partido Unidad Socialista para la Victoria. En esta misma tendencia se 
puede señalar la formación del Movimiento Integrador Latinoamericano de Extracción Social (MILES), partido político lanzado por el líder de la FTV, Luis D’Elía, a principios de 2011.

Si la primera fase del kirchnerismo se caracterizó por completar la ruptura populista y por esta vía lograr un orden hegemónico, el momento aquí analizado supone un desplazamiento de la frontera identitaria que refuerza el sesgo de reafirmación particularista (potencia de la fuerza propia). Ante al discurso liberal-republicano, el gobierno enfatizó su matriz nacional-popular como fuente de democracia sustantiva. Frente al estancamiento de las mejoras estructurales económicas, el gobierno orientó su accionar a políticas de reconocimiento de derechos de fuerte impacto simbólico y político (véase sección Patrón de reproducción económica y politicas públicas ${ }^{18}$ ).

Las elecciones de 2009 hicieron sufrir un retroceso al kirchnerismo dentro del Congreso, que bajó de 116 diputados propios a 87. Este desafío de gobernar sin mayoría propia en el Poder Legislativo no desincentivó al oficialismo, que, de hecho, logró algunas de las leyes que mayor legitimidad le permitieron construir durante este periodo; es decir, negociando con la oposición. Tras el embate "liberal-republicano" que acompañó el conflicto con el agro, se produjo una "radicalización progresista" dentro del kirchnerismo (Varesi, 2013), que le permitió a Cristina Fernández ganar las elecciones presidenciales de 2011 con el 54.11\% de los votos válidos.

De modo claro, el kirchnerismo se convertía en la fuerza política mayoritaria, obligando a los demás partidos a revisar sus identidades y estrategias. Incluso en las elecciones legislativas de 2013, si bien el caudal de votos respecto de 2011 se redujo, la renovación de cargos correspondía a la mala elección de 2009. En tal sentido, el 33.15\% de los votos válidos obtenidos le garantizó la mayoría simple de 132 diputados propios. En el Senado, en cambio, sufrió un leve retroceso (pasa de 41 senadores propios a 39), pero mantuvo también la mayoría simple; es decir, a pesar de las lecturas derrotistas, el gobierno consolidó mayoría propia en ambas cámaras.

Este éxito rotundo en 2011 y relativo en 2013 pareció certificar la estrategia de reposar sobre fuerzas propias, evitando negociar alianzas que no reconocieran esta absoluta primacía. El kirchnerismo reposó cada vez más sobre sus propios cuadros políticos, dirigiéndose en el discurso a sus propios votantes. La expresión repetida por la presidenta y altos funcionarios para desestimar reclamos era: "si no les gusta lo que hace este gobierno, armen un partido y ganen las elecciones”.

18 Se encuentra en páginas anteriores de este mismo artículo [Nota del editor]. 
La exclusión de aliados por el énfasis en la fuerza propia facilitó la creación de dos frentes: Cambiemos (PRO, UCR y CC) y el Frente Renovador (mayormente, el Peronismo Federal). Estos frentes alternaron entre sí las estrategias políticas de oposición frontal y de reconocimiento de algunos logros (continuidad y cambio), pero enfatizando ambos una supuesta "voluntad de diálogo" que se distanciaba de la supuesta prepotencia kirchnerista. Se presentaron como desprovistos de ideología y centrados en la gestión pública eficiente, para diferenciarse de un gobierno pretendidamente corrompido por la excesiva politización. En las elecciones presidenciales de 2015, estas tres fuerzas se repartieron más del $92 \%$ de los votos, ganando en segunda vuelta Cambiemos por un exiguo 2,7\% frente al candidato oficialista Daniel Scioli.

\section{Entre las organizaciones sociales}

La confrontación con "el campo" favoreció un proceso de movilización activa por parte de las organizaciones que apoyaban al gobierno. De hecho, a raíz del mismo, se produjo un súbito acercamiento de artistas e intelectuales progresistas en defensa del gobierno, convocando defender las conquistas obtenidas. La importancia de estas declaraciones de apoyo al gobierno por parte de figuras públicas tuvo un rol muy relevante en la construcción identitaria del kirchnerismo como fuerza nacional popular (Svampa, 2011).

En particular, Carta Abierta (que continuaría publicando intervenciones públicas) reivindicó la política y la discusión pública de las diferencias como cenit democrático, lo que, entendía, era el punto clave del proyecto kirchnerista, y por ello, reivindicable. Se recuperaban las políticas progresistas aplicadas, en particular las ligadas a los derechos humanos.

La enumeración de logros como explicación del apoyo no era novedosa, pero sí que un conjunto de intelectuales irrumpieran en el espacio público dispuestos a aportar a la construcción de una identidad y un relato que contenga esa enumeración de un modo coherente, operando relecturas de la historia y disputando con los grandes medios de comunicación la interpretación de la coyuntura. Recuperando explícitamente las nociones gramscianas, Carta Abierta se dispuso a dar una batalla cultural, que apuntalara el proyecto oficial (Palermo, 2011; Pavón, 2013; Waiman, 2012).

Sin embargo, esto no resultaba suficiente para sostener el proceso kirchnerista. En el marco de este énfasis identitario en la propia fuerza, La Cámpora ganó presencia, en los espacios del Estado y en la agenda mediática, 
haciendo a sus dirigentes figuras conocidas y polémicas. ${ }^{19}$ El perfil juvenil de los militantes de base de la agrupación permitía reafirmar la promesa de renovación de la política que estaba en el horizonte desde 2001, y funcionaba como apelación a una generación que se incorpora a la militancia durante estos años (Vázquez y Vommaro, 2012). De hecho, la agrupación, que no tenía mayor relevancia en la escena nacional, recibió un inusitado impulso a partir del conflicto del campo, componiendo una parte de las fuerzas movilizadas en apoyo al gobierno, en actos de fuerte contenido simbólico.

Además de La Cámpora, nuevas agrupaciones kirchneristas surgieron en este periodo. En julio de 2010 apareció la Corriente de Liberación Nacional (Kolina), creada desde el Ministerio de Desarrollo Social por parte de Alicia Kirchner. Ese año se fundó la Corriente Peronista Descamisados, que lanzó en 2011 un frente juvenil, la JP Descamisados "para profundizar los cambios". Ese mismo año apareció, de la mano del ministro de Trabajo, Carlos Tomada, la agrupación Jóvenes de la Gestión Pública, y, por impulso del entonces ministro de Economía Amado Boudou, La graN macrKo, una corriente de estudiantes y profesionales de ciencias sociales (existía el antecedente de la Asociación de Economía para el Desarrollo de la Argentina, en funciones desde 2008). Como se puede apreciar, existió un esfuerzo explícito por crear espacios para canalizar la militancia desde el Estado, con un carácter centralizado y vertical.

Para evitar una dispersión creciente de los apoyos, se lanzó en abril de 2012 Unidos y Organizados, reuniendo a las organizaciones que se reivindicaban kirchneristas. Al interior de este espacio se reproducirían las tensiones entre fuerzas peronistas y no peronistas del kirchnerismo. Mientras las agrupaciones creadas por el kirchnerismo jugaron un doble rol entre este espacio y el PJ, las fuerzas no peronistas (FORJA, Convocatoria Popular, PC, MILES, Partido Humanista, SI) estaban restringidas a disputar desde Unidos y Organizados su lugar en el FpV.

La militancia kirchnerista tuvo un muy fuerte impulso tras el súbito fallecimiento de Néstor Kirchner en octubre de 2010. El impacto emocional de este evento fue fuerte, leído como la suerte de un dirigente que dejaba la vida en el compromiso político. El funeral del ex presidente resultó una enorme manifestación pública de apoyo, que se transfirió a la presidenta: para muchos, era el momento de mostrar el apoyo explícito al proyecto

19 Nos referimos a José Ottavis, Andrés Larroque, Juan Cabandié, Mariano Recalde, y al propio hijo de Kirchner y Fernández, Máximo Kirchner. La Cámpora surgió como una fusión del MUP, Compromiso K, Juventud Presente y Generación para la Emancipación Nacional en diciembre de 2006. 
ahora liderado por Cristina Fernández, que de otra forma "quedaba sola". Que este evento, por completo fortuito, tuviera semejante efecto político no es fruto de la casualidad, sino que resultó de la lectura retroactiva de los logros del gobierno como parte de las demandas populares.

Debe resaltarse que este énfasis en la militancia propia no sólo relegó a otras organizaciones y partidos, sino también a diversas demandas planteadas al gobierno en distintas oportunidades. El efecto de reposar en quienes se identificaron como kirchneristas como únicos representantes válidos del pueblo fue poner a la vista la sinécdoque: el pueblo excedía al gobierno, sus militantes y sus simpatizantes, que se mostraban como arrebatando lo que era común. Esto dejó abierta la posibilidad de confluencia equivalencial entre demandas, abriendo la posibilidad de una ruptura de tipo populista... ante un gobierno populista (Cantamutto y Hurtado, 2015). Esta posibilidad fue aprovechada por los partidos referidos en la sección 3.3 y las fracciones desplazadas del BEP para ofrecer interpretaciones que alimentaran el descontento con el gobierno.

\section{Centrales sindicales}

El creciente peso de las agrupaciones oficialistas generó tensiones con otros componentes del kirchnerismo. El sindicalismo, al ser desplazado, consideró que era una falta de reconocimiento al apoyo brindado. El crecimiento de estas agrupaciones en las listas oficiales fue cuestionado duramente por Moyano antes de alejarse definitivamente del gobierno en febrero de 2012. Este alejamiento estaba motivado, además de las propias apetencias personales del dirigente, por las presiones de base en torno al deterioro de los salarios reales (Inda, 2012).

Según señalamos en Cantamutto y Hurtado (2015), el gobierno, en lugar de intentar resolver estas tensiones, las templó al calor de políticas como la aplicación de las ganancias a los asalariados y un constante ataque discursivo sobre las direcciones sindicales no aliadas, tildándolas de ser una "aristocracia obrera", a diferencia del "genuino pueblo trabajador" que el gobierno representaría (Castillo, 2012; Inda, 2012).

Se trataba de la misma estrategia utilizada en el conflicto con la Mesa de Enlace: el gobierno se proponía como el único representante legítimo del pueblo ante corporaciones que atentaban contra la comunidad. Se abandonaba así cualquier intento de retenerlos en su lid. La lógica política era plantear la primacía del Estado como representante de la totalidad social, frente a las partes en conflicto (capital-trabajo) y sus corporaciones representativas (Inda, 2012). 
La CGT toleró estas tensiones durante cierto tiempo. La primera división fue en 2008, cuando la fracción ligada a las reformas neoliberales de Luis Barrionuevo se separa de la conducción oficial (Fernández, 2010). En 2010, aparece una división en sentido inverso, cuando una fracción de la CTA (liderada por Hugo Yasky) pasó al apoyo irrestricto del gobierno. En la oposición quedó la fracción conducida por Pablo Micheli. Finalmente, la conducción de la CGT (Moyano) se alejó del gobierno, para acercarse a la CTA Micheli y con el peronismo opositor. Así, después de años, la CTA opositora y la CGT de Moyano convergían en protestas en las calles, demandando aumentos salariales y reclamando contra el impuesto a las ganancias (Cantamutto y Hurtado, 2015; Tagina y Varetto, 2013). Una fracción de la CGT (liderada por Antonio Caló) se mantuvo alineada al gobierno. Desde 2012, las centrales de trabajadores se encuentran divididas en cinco fracciones: dos de ellas con el gobierno y tres en oposición (Payo-Esper, 2013).

\section{Comentarios finales}

El momento inicial de la ruptura populista en Argentina ha sido estudiado en otros trabajos. El presente artículo planteó la posibilidad de periodizar al interior del proceso político kirchnerista en dos grandes fases, separadas por el conflicto de 2008, y posibles de analizarse con base en las alianzas y apoyos que el gobierno concitó en cada caso.

El conflicto de 2008 entre el gobierno y "el campo" impuso un cambio en la estrategia política del kirchnerismo. Como ya señalamos, esto resultó en al menos dos novedades. Por un lado, el intento del gobierno por legitimarse mediante la validación institucional, cuando su propio surgimiento ocurrió a través de una ruptura frente al orden previo; y por otro, una inclinación a afianzarse en la fuerza propia. El kirchnerismo, así, se mantendría como mayoría electoral, afirmando su carácter particular. La segunda fase analizada en este artículo se caracteriza, entonces, por la afirmación particularista de la fuerza en el gobierno, que implicó la consolidación de una identidad propiamente kirchnerista.

Esta afirmación de la particularidad supuso un desmedro por la intención de incorporar otras demandas o actores al propio discurso, presentando fronteras menos lábiles dentro de la comunidad política. Debe enfatizarse que, en desmedro de opciones más radicales, el gobierno no optó por (intentar) expulsar a sus antagonistas de la comunidad política, lo que significaría su final en tanto populismo. En cambio, modificó sus alianzas y discurso de modo tal que se compuso un nuevo mapa político. Las tensiones al interior 
del BEP fueron apaciguadas con el mayor peso de la fracción financiera, y la focalización del conflicto con las fracciones agropecuarias y el grupo Clarín. Se particularizó así el antagonismo con el BEP en estos actores, distinguiéndose de la oposición productivo-especulativo de los primeros años del kirchnerismo.

La oposición partidaria mayoritaria se inclinó a representar estos últimos sectores, desplegando un discurso de corte liberal-republicano, que provocó la reafirmación de la tradición nacional-popular del gobierno. El kirchnerismo se volcó en una estrategia en tres sentidos: a) tratar de controlar el PJ; b) crear nuevas organizaciones destinadas a generar una fuerza propia de apoyo total; y c) conciliar la presencia remanente de organizaciones y partidos aliados en Unidos y Organizados. Ante este panorama y el estancamiento de mejoras estructurales, las centrales sindicales sufrieron un proceso de fragmentación.

Es, entonces, en esta fase cuando el kirchnerismo se consolida no sólo como una fuerza política sino que modifica el campo político, al erigirse como identidad política de gran parte de las fuerzas nacional-populares, aun cuando esto implicó la ruptura de alianzas previas basadas en otras prioridades. De la transversalidad orientada por lo electoral, se pasó a una afirmación particularista con mayores componentes ideológico-políticos.

El cambio de prioridades, estrategias y alianzas dentro del proceso kirchnerista puede iluminar los estudios del populismo en general, como proceso que no acaba al constituirse en gobierno. La impugnación de una fracción desplazada del capital al orden político dio lugar a una nueva configuración del mismo, proceso que no estaba pre-dicho en los pasos iniciales del populismo kirchnerista.

\section{Referencias}

Aboy-Carlés, Gerardo (2005), "Populismo y democracia en la Argentina contemporánea. Entre el hegemonismo y la refundación”, en Estudios Sociales, vol. 28, núm. 1, Argentina: UNL.

Aboy-Carlés, Gerardo (2013), "De lo popular a lo populista o el incierto devenir de la plebs", en Aboy-Carlés, Gerardo, Barros, Sebastián y Melo, Julián [eds.], Las brechas del pueblo. Reflexiones sobre identidades populares y populismo, Argentina: UNDAV Ediciones.

Antón, Gustavo et al. (2011), "Una década en disputa. Apuntes sobre las luchas sociales en la Argentina”, en Modonesi, Massimo y Rebón, Julián [eds.], Una década en movimiento. Luchas populares en América Latina en el amanecer del siglo XXI, Argentina: CLACSO.

Aronskind, Ricardo y Vommaro, Gabriel [comps.] (2010), Campos de batalla. Las rutas, los medios y las plazas en el nuevo conflicto agrario, Argentina: Prometeo.

Artese, Matías et al. (2012), “¿El campo somos todos?: El enfrentamiento de significaciones en torno a la protesta de empresarios agrarios en 2008”, en VII Jornadas de Sociología de la UNLP, Argentina: UNLP.

Balsa, Javier (2010), "Las dos lógicas del populismo, su disruptividad y la estrategia socialista", en Revista de Ciencias Sociales, núm. 17, Argentina: UNQui. 
Convergencia Revista de Ciencias Sociales, núm. 74, 2017, Universidad Autónoma del Estado de México

Barbosa, Sebastián (2012), "La incipiente formación de la identidad popular en el primer kirchnerismo (2003-2007)”, en Pensamento Plural, núm. 10, Brasil: UFPel.

Basualdo, Eduardo (2011), Sistema politico y modelo de acumulación: tres ensayos sobre la Argentina actual, Argentina: Atuel.

Biglieri, Paula y Perelló, Gloria (2007), En el nombre del pueblo. El populismo kirchnerista y el retorno del nacionalismo, Argentina: UNSAMedita.

Bonnet, Alberto (2002), "Que se vayan todos. Crisis e insurrección en Argentina 2001”, en Bajo El Volcán, núm. 5, México: BUAP.

Bonnet, Alberto (2012), "La crisis del Estado neoliberal en la Argentina", en Thwaites, Mabel [ed.], El Estado en América Latina: continuidades y rupturas, Chile: CLACSO/ARCIS.

Bonnet, Alberto y Piva, Adrián (2013), "Un análisis de los cambios en la forma de estado en la posconvertibilidad”, en Grigera, Juan [ed.], Argentina después de la convertibilidad (2002-2011), Argentina: Imago Mundi.

Campione, Daniel (2002), Concentración capitalista y vida politica, Buenos Aires: FISYP. Disponible en: http://fisyp.rcc.com.ar/Concentracion capitalista.pdf [ 1 de agosto de 2015].

Campione, Daniel y Rajland, Beatriz (2006), "Piqueteros y trabajadores ocupados en la Argentina de 2001 en adelante. Novedades y continuidades en su participación y organización en los conflictos" en Caetano, Gerardo [ed.], Sujetos sociales y nuevas formas de protesta en la historia reciente de América Latina, Argentina: CLACSO.

Cantamutto, Francisco J. (2015), "El orden político kirchnerista. Hegemonía y populismo en Argentina, 1998-2015", Tesis para optar por el grado de Doctor en Investigación en Ciencias Sociales, FLACSO México. Disponible en: http://bibdigital.flacso.edu. $\mathrm{mx}: 8080 / \mathrm{dspace} /$ handle/123456789/5623 [1 de agosto de 2015].

Cantamutto, Francisco J. (2016), "Kirchnerism in Argentina: A Populist Dispute for Hegemony", en International Critical Thought, vol. 6, núm. 2, Estados Unidos: Chinese Academy of Social Sciences.

Cantamutto, Francisco J. y Costantino, Agostina (2016), "El modo de desarrollo en la Argentina reciente”, en Mundo Siglo XXI, vol. XI, núm. 39, México: CIECAS-IPN.

Cantamutto, Francisco J. y Hurtado, Héctor (2015), "Gobiernos populistas y demandas irresueltas: los casos de Argentina y Venezuela”, en Vázquez, Daniel [coord.], Articulación, representación y democracia en América Latina, vol. 1, Argentina: CLACSO.

Cantamutto, Francisco J. y Wainer, Andrés (2013), Economia politica de la Convertibilidad. Disputa de intereses y cambio de régimen, Argentina: Capital Intelectual.

Casas, Aldo (2011), "La clase trabajadora a diez años de la rebelión popular", en Revista Herramienta, vol. XV, núm. 46, Argentina.

Castillo, Christian (2012), "El sindicalismo combativo bajo el nuevo gobierno de Cristina Fernández de Kirchner", en VII Jornadas de Sociología de la UNLP, Argentina: UNLP.

Castro-García, Celeste et al. (2009), "El campo en conflicto: disputas y sentidos en torno a la Resolución $\mathrm{N}^{\circ} 125$ ”, en $V$ Jornadas de Jóvenes Investigadores IIGG, Argentina: Instituto de Investigaciones Gino Germani.

Chavez-Solca, Fernando (2014), "Kirchnerismo y Movimientos Sociales. Algunas reflexiones críticas para pensar las implicancias sobre la resignificación del Estado”, en Debates Urgentes, vol. 3, núm. 4, Argentina: CECSO. 
Cortés, Martín (2010), “Movimientos sociales y Estado en el 'kirchnerismo'. Tradición, autonomía y conflicto", en Massetti, Astor, Villanueva, Ernesto y Gómez, Marcelo [eds.], Movilizaciones, protestas e identidades politicas en la Argentina del bicentenario, Argentina: Nueva Trilce.

Costantino, Agostina (2013), "Discurso chacarero y disputas hegemónicas en la pampa argentina”, en Vázquez, Daniel y Aibar, Julio [eds.], Procesos políticos de América Latina. Una lectura critica del neoliberalismo, México: FLACSO México.

Cotarelo, María (2008), "Cronología del Conflicto Social”, en Documentos de trabajo OSAL, núm. 229, Argentina: OSAL.

De Ípola, Emilio (2005), “Falta un elemento integrador en la identidad kirchnerista”, en Página/12, 19 de diciembre, Argentina.

Dikenstein, Violeta y Gené, Mariana (2014), "De la creación de la Alianza a su vertiginosa implosión. Reconfiguraciones de los elencos políticos en tiempos de crisis”, en Pucciarelli, Alfredo y Castellani, Ana [eds.], Los años de la Alianza: La crisis del orden neoliberal, Argentina: Siglo XXI.

Fair, Hernán (2009), "El debate 'nacionalismo sano' versus 'patriotismo republicano”, en Colección, vol. XV, núm. 20, Argentina: UCA.

Féliz, Mariano y López, Emiliano (2012), Proyecto neodesarrollista en la Argentina. ¿Modelo nacional-popular o nueva etapa en el desarrollo capitalista?, Argentina: Herramienta-El Colectivo.

Fernández, Arturo (2010), "El sindicalismo argentino frente al Bicentenario: una reseña histórica”, en Revista de Trabajo, vol. 6, núm. 8, Argentina: Ministerio de Trabajo, Empleo y Seguridad Social.

Fernández de Kirchner, Cristina (2008), Discurso en el Acto por la convivencia y el diálogo, 1 de abril, Argentina. Disponible en: http://www.casarosada.gob.ar/informacion/ archivo/16854-blank-16096543 [12 de junio de 2014].

Gaggero, Alejandro y Wainer, Andrés (2006), "Burguesía nacional-Crisis de la Convertibilidad: el rol de la UIA y su estrategia para el (tipo de) cambio", en Realidad Económica, núm. 204, Argentina: IADE.

Guerrero-Iraola, Jerónimo (2011), "Apuntes sobre hegemonía. Disquisiciones acerca de la construcción de sentido del 'kirchnerismo”', en Question, vol. 1, núm. 31, Argentina: UNLP.

Inda, Graciela (2012), "La disputa por la hegemonía político-ideológica: trabajadores y sindicatos en el discurso presidencial kirchnerista (Argentina, 2007-2012)", en Estudios Sociales Contemporáneos, núm. 7/8, Argentina: UNCu.

Iñigo-Carrera, Nicolás y Cotarelo, María (2006), "Génesis y desarrollo de la insurrección espontánea de diciembre de 2001 en Argentina”, en Caetano, Gerardo [ed.], Sujetos sociales y nuevas formas de protesta en la historia reciente de América Latina, Argentina: CLACSO.

Laclau, Ernesto (2006), La razón populista, México: Fondo de Cultura Económica.

Larrondo, Martín y Patrici, Nicolás (2005), "La Crisis de Argentina: Reflexión sobre la Representación Política y la Democracia”, en Convergencia. Revista de Ciencias Sociales, vol. 12, núm. 38, México: Universidad Autónoma del Estado de México.

Montero, Ana y Vincent, Lucía (2013), “Del 'peronismo impuro' al 'kirchnerismo puro': la construcción de una nueva identidad política durante la presidencia de Néstor Kirchner en Argentina (2003-2007)”, en Postdata, vol. 18, núm. 1, Argentina. 
Moreira, Carlos y Barbosa, Sebastián (2010), "El kirchnerismo en Argentina. Origen, apogeo y crisis. Su construcción de poder y forma de gobernar", en Sociedade E Cultura, vol. 13, núm. 2, El Salvador: UFG.

Muñoz, Antonia (2004), "Los discursos de la desocupación y la pobreza, las organizaciones de desocupados y la esfera político estatal”, en Lavboratorio, vol. 4, núm. 15, Argentina: UBA.

Muñoz, Antonia (2010), Sísifo en Argentina. Orden Conflicto y sujetos politicos, México: Editorial Universitaria Villa María, Plaza y Valdés.

Naishtat, Francisco et al. (2005), Tomar la palabra: estudios sobre la protesta social y acción colectiva en la Argentina contemporánea, Argentina: Prometeo.

Natalucci, Ana y Schuttenberg, Mauricio (2013), "Pensar el kirchnerismo: estado actual de los estudios sobre movimentismo e identidades nacional-populares”, en Retamozo, Martín, Schuttenberg, Mauricio y Viguera, Aníbal [eds.], Peronismos, izquierdas $y$ organizaciones populares. Movimientos e identidades politicas en la Argentina contemporánea, . Argentina: UNLP.

Palermo, Vicente (2011), "Consejeros del príncipe. Intelectuales y populismo en la Argentina de hoy”, en RECSO. Revista de Ciencias Sociales, núm. 2, Uruguay: UCU.

Panero, Marcelo (2011), “Nuestro país rural'. La dimensión política del pensamiento económico de la Sociedad Rural Argentina”, en IX Jornadas de Sociología de la UBA, Argentina: UBA.

Pavón, Héctor (2013), “Argentina: el regreso de los intelectuales públicos”, en Nueva Sociedad, núm. 245, Argentina: Fundación Friedrich Ebert.

Payo-Esper, Mariel (2013), "Las huelgas generales en el período 2002-2012. Notas sobre su dinámica y la relación con la conflictividad laboral”, en VII Jornadas de Jóvenes Investigadores, Argentina: Instituto de Investigaciones Gino Germani.

Perelmiter, Luisina (2010), "Militar el Estado. La incorporación de movimientos sociales de desocupados en la gestión de políticas sociales. Argentina (2003-2008)”, en Massetti, Astor, Villanueva, Ernesto y Gómez, Marcelo [eds.], Movilizaciones, protestas e identidades politicas en la Argentina del bicentenario, Argentina: Nueva Trilce.

Poulantzas, Nicos (1980), Estado, poder y socialismo, España: Siglo XXI.

Raus, Diego (2014), "El Partido Justicialista en el gobierno de la Alianza”, en Pucciarelli, Alfredo y Castellani, Ana [eds.], Los años de la Alianza: La crisis del orden neoliberal, Argentina: Siglo XXI.

Retamozo, Martín (2011), “Movimientos sociales, política y hegemonía en Argentina”, en Polis. Revista Latinoamericana, núm. 28, Chile: CISPO.

Rinesi, Eduardo (2011), "Notas para una caracterización del kirchnerismo", en Debates y Combates, vol. 1, núm. 1, Argentina.

Rodríguez, Gabriela y Freibrun, Nicolás (2011), "La república es de los otros ¿o puede ser mía? Un dilema para el intelectual kirchnerista”, en IX Jornadas de Sociología de la $U B A$, Argentina: UBA.

Sanz-Cerbino, Gonzalo (2012), "Burguesía agraria, conflictividad política y quiebres institucionales. Argentina, 1975-2008”, en Polis. Revista Latinoamericana, núm. 31, Chile: CISPO.

Schorr, Martín (2001), Atrapados sin salida?: la crisis de la convertibilidady las contradicciones en el bloque de poder económico, Argentina: FLACSO. 
Schuttenberg, Mauricio (2011), “La reconfiguración de las identidades 'nacional populares'. Los puentes discursivos para la inserción de tres tradiciones políticas en el espacio 'transversal kirchnerista', en Sociohistórica, núm. 28, Argentina: UNLP.

Seoane, José (2002), "La debacle neoliberal. Protesta social y crisis política en Argentina”, en Íconos, núm. 13, Ecuador: FLACSO Ecuador.

Svampa, Maristella (2011), “Argentina, una década después. Del 'que se vayan todos' a la exaltación de lo nacional-popular”, en Nueva Sociedad, núm. 235, Argentina: Fundación Friedrich Ebert.

Svampa, Maristella y Pereyra, Sebastián (2004), Entre la ruta y el barrio: la experiencia de las organizaciones piqueteras, Argentina: Biblos.

Tagina, María Laura y Varetto, Carlos (2013), “Argentina: del apogeo electoral a la inminencia de la crisis sucesoria”, en Revista de Ciencia Política, vol. 33, núm. 1, Chile: Pontificia Universidad Católica de Chile.

Varesi, Gastón (2013), "Modelo de acumulación, dinámica política y clases sociales en la Argentina posconvertibilidad”, en Grigera, Juan [ed.], Argentina después de la convertibilidad (2002-2011), Argentina: Imago Mundi.

Vázquez, Melina y Vommaro, Pablo (2012), La fuerza de los jóvenes: aproximaciones a la militancia kirchnerista desde La Cámpora, Argentina: CLACSO.

Waiman, Javier (2012), "El debate sobre la hegemonía cultural kirchnerista”, en VII Jornadas de Sociología de la UNLP, Argentina: UNLP.

Yabkowski, Nuria (2012), "La negación de la parte: la crisis de representación política argentina”, en Nómadas. Revista Crítica de Ciencias Sociales y Jurídicas, número especial, España: UCM.

Francisco J. Cantamutto. Doctor en Investigación en Ciencias Sociales (FLACSO México), Maestro en Ciencias Sociales (FLACSO México). Becario posdoctoral de CONICET en el IDAES de la UNSam. Principales líneas de investigación: economía política y los procesos políticos de América Latina, con especial referencia a Argentina. Publicaciones recientes: Cantamutto, Francisco J., "Construcción de hegemonía y Estado: algunas bases teóricas”, en Estudios Sociales del Estado, núm. 1, vol. 1 (2015); Costantino, Agostina y Cantamutto, Francisco J., "Patrón de reproducción del capital y clases sociales en la Argentina contemporánea”, en Sociológica, año 29, núm. 81, enero-abril (2014); Cantamutto, Francisco J. y Wainer, Andrés, Economía politica de la Convertibilidad. Disputa de intereses y cambio de régimen, Colección Claves para Todos, dirigida por José Nun, Buenos Aires (2013).

Recepción: 28 de abril de 2015.

Aprobación: 12 de octubre de 2016. 
